\title{
DURAND DE HUESCA Y LA LUCHA CONTRA EL CATARISMO EN LA CORONA DE ARAGÓN
}

\author{
DURAND OF HUESCA AND THE POLEMIC AGAINST THE CATHARS \\ IN THE CROWN OF ARAGON
}

\author{
SERGI GRAU TORRAS \\ Licenciado en Historia \\ Universidad Autónoma de Barcelona
}

\begin{abstract}
Sumario: Durand de Huesca escribió tres tratados contra la herejía y fue prior de los Pobres Católicos, una comunidad apostólica basada en los ideales de pobreza valdenses. Los Pobres Católicos fundaron escuelas de estudio y hospitales para el cuidado de los enfermos y tuvieron una importante incidencia social y cultural en la Corona de Aragón. La primera obra de Durand, el Liber Antiheresis, conservada en la Biblioteca Nacional de Madrid, es un tratado contra la herejía y es una de las pocas fuentes que existen en España para conocer la doctrina del catarismo y los orígenes de la valdesía. Este tratado sirvió también como base para obras posteriores.
\end{abstract}

Palabras clave: Durand de Huesca; Catarismo; Valdesía; Pedro Valdés; Pobres Católicos, Liber Antiheresis; Corona de Aragón; Herejía.

\begin{abstract}
Durand of Huesca wrote three manuscripts against heresy and he was a prior from the Catholics Poor, an apostolic community based on the waldensian's ideal of poverty. The Catholics Poor founded schools of study and hospitals to care and assist patients and poors, and they had an important social and cultural incidence in the Crown of Aragon. The first work of Durand, Liber Antiheresis, preserved in the National Library of Madrid, is treaty against the heresy and it is one of the few sources that exists in Spain to know about the doctrine of catharism and the origins of the waldensian. This source serves was also used as a base for later polemic works.
\end{abstract}

Key words: Durand of Huesca; Catharism, Waldenses, Pedro Valdés, Catholic Poors, Liber Antiheresis, Crown of Aragon; Heresy.

\section{SUMARIO}

1. Presentación.- 2. Los orígenes de Durand de Huesca y la valdesía.- 3. El Liber Antiheresis de Madrid. Una fuente para el estudio de la valdesía y del catarismo.- 4. Los Pobres Católicos y la escuela de la Corona de Aragón.- 5. Influencia de la obra de Durand.- 6. Conclusiones. 


\section{PRESENTACIÓN ${ }^{1}$}

Con el paso del tiempo han perdurado varios testimonios sobre la actividad literaria que un grupo de valdenses convertidos al catolicismo del norte de Cataluña y del Languedoc realizaron contra los cátaros. Esta actividad se centra en una polémica escrita que nos revela la eficacia que estas controversias tuvieron desde finales del siglo XII al XIII en la lucha contra el catarismo, y también nos introduce en el mundo de los movimientos apostólicos que aparecieron durante esta época. En la Corona de Aragón, uno de los protagonistas en esta disputa fue Durand de Huesca. Durand era un clérigo letrado que dejó escritos como mínimo tres tratados contra la herejía ${ }^{2}$ - concretamente contra el catarismo- de los cuales dos se encuentran en la Biblioteca Nacional de Madrid, y es autor también de un cuarto tratado sobre Teología. ${ }^{3}$ Además, Durand fue el motor de una comunidad de personas conocida como los Pobres Católicos, unidas por los mismos ideales apostólicos y con una importante incidencia cultural y social en distintas regiones de Europa. Esta comunidad se fundamentó por un lado en la predicación y en la formación de clérigos instruidos para combatir a la herejía, y por otro lado se dedicaron a las necesidades humanas construyendo hospitales para el cuidado de los enfermos y niños abandonados, con prácticas que no siempre estuvieron cerca de la ortodoxia religiosa. En este artículo queremos presentar la importancia de la figura de Durand de Huesca. Para hacerlo analizaremos, en primer lugar, su vida a través de los documentos que existen. En segundo lugar, analizaremos su primera gran obra, el Liber Antiheresis, conservado en la Biblioteca Nacional de Madrid, que se convirtó en un manual contra la herejía y fue el primer estadio de la controversia que se desarrolló a principios del siglo XIII contra el catarismo en la que intervendrán otros autores. Además, este manuscrito es una de las pocas fuentes que existen en España para el estudio de la doctrina del catarismo y los orígenes de la valdesía. Para terminar valoraremos la incidencia cultural de Durand y los Pobres Católicos en el ámbito de la Corona de Aragón, cuyo centro principal fue Elna.

\footnotetext{
${ }^{1}$ En primer lugar, agradecer a la Biblioteca del Centro de Estudios Cátaros de la Fundación Rosacruz de Barcelona por toda la información y todo el material documental facilitado que ha sido de gran utilidad para la realización de este artículo.

${ }^{2}$ En orden cronológico: el Liber Antiheresis, el Opusculum contra hereticos y el Liber contra Manicheos.

${ }^{3}$ Mary A. ROUSE, Richard H. ROUSE, The Schools and the Waldensians: a new work by Durand of Huesca en Christendom and its Discontents: Exclusion, Persecution, and Rebellion, 1000-1500, (eds. Scott L. WAUGH and Peter D. DIEHL), Cambridge University Press, Cambridge, 1996, pp. 86-111.
} 


\section{LOS ORÍGENES DE DURAND DE HUESCA Y LA VALDESÍA}

Existen pocas fuentes que nos informen sobre la actividad de Durand ${ }^{4}$. Marcelino Menéndez Pelayo ya notaba que era caso rarísmo y aislado ${ }^{5}$. Sabemos por Inocencio III que Durand estuvo al frente de una comunidad apostólica conocida como los Pobres Católicos -Pauperes Catholici-y el mismo papa respaldó su actividad predicadora a través de varias cartas que mandó a los obispos de la Corona de Aragón, Occitania y Lombardía. ${ }^{6}$ Guillaume de Puylaurens en su Chronique nos informa que Durand de Huesca fue su prior y compuso algunos escritos contra los herejes y también que vivieron varios años en Cataluña?

Como se percató Esteban Sarasa, en la catedral de Huesca existe un documento de 1181 que lleva la firma de Durandus scriptor ${ }^{8}$. Aunque ésta es la primera y la única referencia en esta serie que contenga el nombre de Durand, este documento nos muestra su calidad de clérigo y copista. De este modo, fue en la escuela catedralicia de Huesca donde adquirió su formación eclesiástica y donde muy probablemente conoció las biblias hispanas que posteriormente utilizó. Por sus escritos sabemos que conocía el latín, tenía nociones de griego, y dominaba también el catalán y el occitano. Es muy probable, como apunta Jordi Ventura, que proviniera de las migraciones occitanas del siglo XII que se instalaron en algunos barrios de Huesca, pues en las obras que dejará escritas, el latín se mezcla con muchas referencias lingüísticas catalanas y occitanas ${ }^{9}$. Durante esta etapa en Huesca hay que destacar el movimiento ascético-monacal que protagonizó el canónigo Galindo de Perola del que Durand pudo formar parte ${ }^{10}$. Éste grupo se dedicó a atender a los pobres de la ciudad en un centro benéfico de limosnas, llamado San Miguel, que contaba con una iglesia, un cementerio y un hospital atendido por

\footnotetext{
${ }^{4}$ Sobre Durand de Huesca ver Christine Thouzellier, Catharisme et valdéisme en Languedoc a la fin du XII et au début du XIII siècle: politique pontificale, controverses, Presses Universitaires de France, 1966; Jordi VENTURA SUBIRATS, La valdesía en Cataluña, "Boletín de la Real Academia de las Buenas Letras de Barcelona",(=BRABLB) XXIX, 1961-1962. pp. 275317; el mismo artículo fue publicado posteriormente en el libro J. VENTURA, Els heretges catalans, Barcelona, Ed. Selecta, 1976. Carlo PAPINI, Valdo di Lione e $i$ «poveri nello spirito». Il primo secolo del movimento valdese $1170-1270$, Claudiana, Torino, 2002. Las partes centradas en Durand: pp. 204-222 y pp. 252-273.

${ }^{5}$ Marcelino MenÉndeZ y Pelayo, Historia de los heterodoxos españoles, vol. I, p. 455.

${ }^{6}$ Se han conservado 14 cartas sobre la actividad de Durand en la Corona de Aragón recopiladas en Demetrio MANSILLA, La documentación pontificia hasta Inocencio III, Roma, Instituto Español de Estudios Eclesiásticos, 955 pp. 410-509. Su actividad se centra entre diciembre de 1208 hasta mayo de 1212. También se han conservado cartas dirigidas a los obispos de la Lombardía.

${ }^{7}$ Guillaume De PuYlaurens, Chronique 1145-1275, Toulouse, Le Pérégrinateur Editeur, 1996 , p. 55.

${ }_{8}^{8}$ Antonio DURAn Gudiol, Colección diplomática de la catedral de Huesca, I, 1956, pp. 362-363, doc. 373 .

${ }^{9}$ J. VENTURA, La valdesía $\mathrm{p}$ 297. Una síntesis sobre el debate en torno al origen de Durand en C. PAPINI, Valdo, pp. 204-208.

${ }^{10}$ Esteban SARASA SÁNCHEZ, Durand de Huesca, un heterodoxo en la Edad Media en Miscelanea de Estudios en honor de D. Antonio Gudiol, Sabiñánigo, 1981, pp. 225-238
} 
religiosos. En mayo de 1184, el movimiento de Huesca era aprobado por el papa Lucio III y quedaba puesta bajo control económico del cabildo catedralicio $^{11}$. Aunque no hay datos concluyentes, Durand pudo participar con ellos ya que la naturaleza de este movimiento, el pauperum christi servitio, constituyó la dinámica que marcó toda su vida; treinta años después, el ascetismo, la vida comunitaria, la pobreza, así como la creación de hospitales para la ayuda y el cuidado a los pobres y a los enfermos fueron la base de su actividad.

Durand escribió su primer libro cuando era un discípulo y admirador de Pedro Valdés, del que nunca se olvidará. No sabemos cuándo se interesó por los ideales valdenses ni cuándo entró en contacto con ellos. Los inicios de la valdesía en la Corona de Aragón no son muy conocidos ni se conoce realmente el grado de expansión que adquirió aunque hay constancia de la presencia de este movimiento durante la última década del siglo XII. El primer documento que nos remite a su presencia en la Corona de Aragón es el decreto que propugnó en 1194 Alfonso el Casto en Lleida en el que se instaba a abandonar el territorio a los valdenses, los Pobres de Lyon y a todos los otros herejes, condenados por la Iglesia ${ }^{12}$. En 1198, el mismo decreto fue ratificado por Pedro el Católico en Girona. A pesar de la prohibición, estos decretos no llegaron a aplicarse de forma estricta sino que pudo ser una estrategia diplomática que se realizó el mismo año que el papa Inocencio III, llegaba a la silla pontifica ${ }^{13}$. En la Corona de Aragón, las relaciones entre la nobleza catalana y occitana con el catarismo no implicó una persecución de este movimiento, como tampoco de la valdesía. Las persecuciones empezaron años más tarde, con el establecimiento de la Inquisición, lo que propició que ambos movimientos pudieran existir y expandirse a finales del siglo XII y principios del XIII por el territorio catalán.

La valdesía fue un movimiento que se originó en Lyon. La Crónica de Laon $^{14}$ compuesta hacia 1220 nos informa sobre sus orígenes. Pedro Valdés era un rico comerciante de Lyon que a causa de unas circunstancias fortuitas quedó tan preocupado por la salvación de su vida que buscó y preguntó a un clérigo. Éste le remitió al texto de San Mateo $(19,21)$ : “Si quieres ser perfecto, toma lo que tienes y dálo a los pobres, y tendrás tesoros en los cielos; después ven y sígueme”. Entonces Valdés repartió en cuatro partes sus posesiones. Una de ellas fue para su mujer, otra para sus hijas, otra para los pobres y la última parte la destinó a las víctimas que sus injusticias como comerciante habían provocado. Y después, en 1173, renunciando a su fortuna,

${ }^{11}$ D. Gudiol, Colección, p. 388, doc. 390.

${ }^{12}$ Cebrià BARAUT, Els inicis de la Inquisició al bisbat d'Urgell (segles XII-XIII), "Urgellia”, XIII (1996-1997), pp. 407-438. Documentos 1 y 2 del apendice: persequendos censuerunt valdenses, videlicet qui vulgariter dicuntur cabatati qui et alio nomine se vocant pauperes de Lugduno et omnes alios hereticos quorum non est numerus nec nomina sunt nota a sancta Ecclesia anathematitzatos ab omni regno et potestate nostra tamquam inimicos crucis Christi christianaque fidei violatores".

${ }^{13}$ Jordi Ventura, Pere el Catòlic i Simó de Montfort, Barcelona, 1996, pp. 49-55

${ }^{14}$ Un breve análisis sobre la Crónica: Chronique anonyme de Laon en Enchiridion Fontium Valdensium, II, (ed. Giovanni GoNNET) Torino, 1998, pp.21-24 
empezó a predicar. Al cabo de poco tiempo, Pedro había agrupado a su alrededor a un grupo de hombres y mujeres, unidos todos ellos por el mismo ideal de pobreza evangélica. Sus miembros, laicos y religiosos, predicaban por las plazas de Lyon. Una de las aportaciones de Valdés fue iniciar las primeras traducciones de la Biblia y otros textos patrísticos en lengua vulgar, que impulsaron las primeras traducciones catalanas. Esta pequeña comunidad que Pedro había formado pronto representó un gran problema para Roma. Sus críticas iban dirigidas contra la jerarquía eclesiástica y contra su modo de vivir, que estaba muy alejado ya del ideal cristiano. Con ellos predicaban mujeres, habían traducido, como también harán los cátaros, las Sagradas Escrituras a la lengua vulgar, rompiendo sin permiso el monopolio del conocimiento que se adjudicaba la Iglesia. La comunidad de Pedro, por sus ideales de pobreza fue conocida como los "Pobres de Lyon" y fue condenada por el papa Lucio III en 1184 como un cisma herético, justo en el año que el mismo papa aprobaba el movimiento ascético-monacal de Huesca. El grupo de Pedro fue expulsado de Lyon y fueron perseguidos. A pesar de ello, Pedro y los suyos siguieron predicando y tuvieron una gran influencia en distintos lugares de Europa. Finalmente terminaron por rechazar la autoridad de la Iglesia y con los años, el movimiento que había iniciado se radicalizó.

La siguiente noticia relacionada con Durand nos la facilita Guillaume de Puylaurens. El cronista nos informa que el oscense estuvo presente entre agosto y septiembre de 1207 en uno de los últimos coloquios y debates abiertos que hubo en Pamiers (Ariege) entre católicos y herejes ${ }^{15}$. Según Guillaume, en esta ocasión, el oscense estaba plenamente integrado en la valdesía occitana. En 1207, Pedro Valdés ya había muerto y la valdesía estaba dividida entre una facción más radical y otra más moderada. No se sabe cuándo Durand se desplazó hacia Occitania, pero lo hizo muy probablemente después del decreto de Alfonso, en busca de un lugar donde la valdesía tuviera mucha más libertad que en la Corona de Aragón, o quizás lo hizo, porque era en Occitania donde tenían lugar los grandes debates teológicos sobre las herejías, algo que siempre preocupó a Durand. En 1207 se encontraron católicos, cátaros y valdenses que polemizaron de forma abierta sobre los errores de la fe. A Pamiers llegaron católicos de todos los lugares; entre ellos, se encontraba el obispo castellano Diego de Osma, y con él probablemente Domingo de Guzmán, el futuro santo. También había cátaros, pero quien tenía una mayor presencia eran los valdenses. Durand y su grupo estaban allí. Es probable que en Pamiers se encontraran antiguos compañeros de la península. Este encuentro, del que no ha perdurado más que la breve información que nos facilita Guillaume, debió ser como otra de las muchas disputas abiertas entre cristianos heterodoxos y ortodoxos que se realizaban en la época, pocos años antes que empezaran las persecuciones y la Inquisición hiciera sus

\footnotetext{
${ }^{15} \mathrm{G}$. DE PUYlaUREnS, Chronique, p. 55; Sobre el debate en Pamiers ver Marie-Humbert VICAIRE Recontre a Pamiers des courants vaudois et dominicain (1207), "Cahiers de Fanjeaux",
núm. 2: Vaudois languedociens et Pauvres catholiques, Privat éditeur, Fanjeaux (1967), pp. 163194.
} 
estragos. La experiencia del diálogo inspiró a Durand su nuevo ideal de Iglesia. Después del debate de Pamiers, en otoño de 1207, Durand con algunos compañeros occitanos viajaron a Roma para establecer su reconciliación de fe con la Iglesia y presentar la profesión de una nueva comunidad conocida como los Pobres Católicos. Una comunidad que se fundamentó en los ideales valdenses pero adaptados por Durand en el seno de una ortodoxia religiosa que nunca fue entendida como tal ${ }^{16}$.

\section{EL LIBER ANTIHERESIS DE MADRID. UNA FUENTE PARA EL ESTUDIO DE LA VALDESÍA Y DEL CATARISMO}

Cuando Durand escribió su primera obra, el Liber Antiheresis, fue anterior a la reunión de Pamiers. Incluso es muy probable que fuera antes de viajar a Occitania. El padre dominico Antoine Dondaine, uno de los grandes historiadores del catarismo del siglo XX, descubrió el manuscrito durante la década de $1940^{17}$. El documento, anónimo, atrajo su atención por la profesión de fe de Pedro Valdés que le precede. Esta profesión es única para el estudio de los orígenes de la valdesía, y es una de las pocas referencias directas que hay sobre los preceptos con los que Pedro Valdés fundamentó su predicación. Años después de que Dondaine hubiera descubierto el documento, presentaba en 1955 en Roma uno de sus trabajos realizado sobre el texto y el contenido del Liber. Su estudio y su análisis concluyeron que el autor no podía ser otro que el mismo Durand ${ }^{18}$.

Posteriormente los trabajos críticos de Cristine Thouzellier, han establecido que el manuscrito fue escrito entre 1190 y $1194^{19}$. De este tratado se conservan dos versiones; una en Madrid, en cuarto, que es la versión más antigua y es la que muestra su estado primogénito y original, y otra posterior

\footnotetext{
${ }^{16}$ Sobre los Pobres Católicos ver C. THOUZELliER, Catharisme; "Cahiers de Fanjeaux", 2 : Vaudois languedociens et Pauvres catholiques, Privat éditeur, 1967.

${ }^{17}$ Antoine DondaInE, Aux origenes du Valdéisme: une profesión de foi de Valdès, "Archivum Fratrum Predicatorum" (=AFP), XVI (1946), pp. 191-235; el mismo artículo incluido también en el libro de A. DONDAINE, Les hérésies et l'Inquisition XXII-XIII siẹcles, Variorum collected Studies, 1999. Sobre la importancia del padre Antoine Dondaine en la historia del catarismo véase Yves DossAT, La découverte des textes cathares: le Père Antoine Dondaine, "Cahiers de Fanjeaux", núm 14 (1979) Historiographie du catharisme, pp. 343-359.

${ }^{18}$ A. DondaINE, Durand de Huesca et la polemique anti-cathare, "AFP", XXIV (1959), pp. 228-277. El artículo está incluido también en el libro de A. DONDAINE, Les hérésies .Fue la comparación del manuscrito con el Contra Manicheos lo que concluyó su autoría.

${ }^{19} \mathrm{C}$. THOUZELlIER, Controverses Vaudois-Cathares a la fin du XIIe siècle (d'après le livre II du «Liber Antiheresis», ms. Madrid 1114 et les sections correspondantes du ms. BN lat. 13446 "Archives d'Histoire Doctrinal et Littéraire du Moyen Age", XXVII, 1960 (1961), pp.137-227. El mismo artículo se encuentra también en C. THOUZELLIER, Hérésie et hérétiques. Vaudois, Cathares, Patarins, Albigeois, Roma, Edizioni di Storia e Letteratura, 1969, pp. 81-188. Según indica Papini, el primer propietario del manuscrito Giacomo Beccheto lo adquirió en el siglo XV a Baldassarre di Legnano y no fue hasta 1757 que entró a formar parte de la biblioteca del conde de Miranda. Pero Durand realizó varios viajes a Italia llevando consigo, muy probablemente el manuscrito. Allí estuvo en contacto con teólogos a los que en algún momento pudo ceder el manuscrito y quedarse en Italia hasta su adquisición por parte del conde de Miranda. En mi opinión su procedencia catalanoaragonesa es muy factible.
} 
que se conserva en París ${ }^{20}$, escrito entre 1195 y 1200 y con algunas diferencias con la copia anterior. La versión de Madrid del Liber, procede de la colección privada del conde de Miranda, ocupa 120 folios y está dividida en dos partes; el Libro I con 26 capítulos y el Libro II con 5 capítulos que suman los 31 capítulos de los que se compone la obra. Esta segunda parte es el núcleo de la polémica teológica contra el catarismo. La profesión de Valdés ocupa dos folios, y la obra incluye un preámbulo que justifica el libro. El texto, escrito en latín, contiene influencias lingüísticas catalanas y occitanas muy marcadas, lo que nos ayuda a identificar la procedencia del autor. En su versión parisina, los dos capítulos quedan agrupados en una única parte, se simplifican las abreviaturas y las citas, aunque trata los mismos temas. El trabajo crítico de Kurt-Victor Selge nos indica que la versión parisina contiene las mismas influencias lingüísticas que la edición de Madrid ${ }^{21}$. Ambas ediciones incluyen la profesión de fe de Pedro Valdés al inicio del libro de forma idéntica.

La primera edición del Antiheresis está escrita como muy tarde en 1194 lo que supone que el manuscrito podría proceder de algún lugar de la Corona de Aragón, mientras que la segunda versión habría sido realizada por Durand, o un compañero suyo muy cercano, en el norte de Cataluña o en Occitania. 1194 es el año que aparece el decreto contra los valdenses en la Corona de Aragón. La posibilidad que Durand escribiera el Antiheresis en territorio catalanoaragonés supone que habría conocido el catarismo en territorio oscense o catalán en una fecha anterior a 1190, lo que es factible ya que el catarismo tuvo cierta presencia en la Corona de Aragón ${ }^{22}$. Como fecha muy temprana podemos establecer el año 1165 como primer momento en el que el catarismo hubiera penetrado en Cataluña, extendiéndose desde Occitania hasta las tierras meridionales de Cataluña, como Lleida y las tierras colindantes con Aragón, y pudo incluso haber llegado hasta Tortosa ${ }^{23}$. Años más tarde, en 1194 cuando apareció el primer decreto contra la herejía el catarismo ya existía en el territorio. Aunque en el decreto contra la herejía no se cite explícitamente al catarismo, éste era la herejía por excelencia, y todos los polemistas católicos, incluso Durand, cuando se refieren a la herejía la vinculan con el catarismo. Dos años después del decreto, la presencia de un noble catalán defensor del catarismo, Arnau de Castellbó relacionado con la problemática de 1196 en la diócesis de Urgell, reafirmaría cómo este movimiento habría penetrado más intensamente en algunas regiones de

\footnotetext{
${ }^{20}$ Existe la edición crítica de la versión parisina del Liber Antiheresis en Kurt-Victor SELGE, Die erstern Waldenser II: Der Liber Antiheresis des Durandus von Osca, Berlín. 1967 (volumen II). El mismo Selge retrasa la elaboración del segundo libro del manuscrito de Madrid en torno a $1186-1187$.

${ }^{21}$ De la versión parisina Selge nos indica que "die scrhift ist südfranzöische oder nordspanische”, es decir, que está escrito en occitano o catalán, en K-V. SELGE, op. cit., p. XVIII, Enileitung, vol. If.

${ }^{22}$ J. VENTURA, El catarismo en Cataluña, "BRABLB”, XXVIII (1959-1962), pp. 75-168.

${ }^{23}$ Bernard HAMILTON, The cathar council of Saint-Félix reconsidered , "AFP”, 48 (1978), pp. $23-53$.
} 
Cataluña ${ }^{24}$ y la declaración de Arnau Bretós de Berga de 1244, describe cómo en 1214 el catarismo estaba en pleno funcionamiento en Cataluña ${ }^{25}$.

Además, una de las principales vías de expansión del catarismo fue a través del comercio y de la industria textil. Existen referencias sobre la industria del tejido en Huesca, así como en distintas ciudades de Cataluña, por lo que es muy factible que durante la década de los años noventa del siglo XII, Durand pudiera haber conocido los argumentos cátaros en la Corona de Aragón, que de hecho, eran los mismos que los Occitanos. Y en esta época conoció al catarismo escuchando cómo predicaban pues como advierte en su Antiheresis, refutaba a la herejía según hemos oído ${ }^{26}$, mientras que años más tarde lo conoció aún más por una apología cátara escrita que le llegó a sus manos y le permitió polemizar con el tratado fragmento por fragmento para reproducirlo en su última obra, el Liber contra Manicheos.

Ante todo esto hay una cuestión ¿Cómo conoció durante esos años la profesión de fe de Pedro Valdés? Quizás porque a pesar de la prohibición papal de 1184, la valdesía no fue un gran problema en la Corona de Aragón, y no lo representó hasta que el catarismo empezó a aparecer de forma más intensa durante la década de 1190. Y aún así, en la Corona de Aragón, la valdesía siempre estuvo a la sombra del catarismo. En Lyon, durante varios años, los valdenses tuvieron el respaldo del arzobispo. No fue hasta 1183 que empezaron los problemas, $\mathrm{y}$ al año siguiente fueron expulsados de la ciudad ${ }^{27}$. A partir de esa fecha no hay presencia de la valdesía en Lyon, y sus ideales se expanden hacia Occitania e Italia. En estos diez años las doctrinas valdenses llegaron a la Corona de Aragón.

En el Liber Antiheresis se encuentra reproducida una de las escasas copias que existen sobre la profesión de Pedro Valdés que realizó entre 1180 y 1181 y que Durand utilizó como preludio de su obra. Esta profesión de fe nos revela la búsqueda de la perfección cristiana con la observación estricta de los evangelios basada en la más absoluta pobreza, el elemento fundamental de la valdesía. La Confessio fidei Valdesii empieza así:

En el nombre del Padre y del Hijo y del Espíritu Santo y de la beatísima siempre virgen María. Sepan todos los fieles que yo Valdés (Valdesius) y todos mis hermanos, ante los santos evangelios, creemos en el corazón, entendemos en la fe, confesamos con la boca, y afirmamos con simples

\footnotetext{
${ }^{24} \mathrm{C}$. BARAUT La presencia i la repressió del catarisme al bisbat d'Urgell (segles XII-XIII), "Urgellia", 12 (1994-95) pp 487-524; Carles GASCON CHOPO, Crisis social, espiritualidad y herejía en la diócesis de Urgel (siglos XII-XIII). Los orígenes y la difusión de la herejía cátara en la antigua diócesis de Urgell, "Espacio, Tiempo y Forma", serie III, t. 16, 203, pp. 73-106.

${ }^{25} \mathrm{La}$ declaración de Arnau Bretós de Berga se encuentra en la BN de París, fondo Doat, vol. XXIV, ff. 182r-193r; en J. VENTURA, Catarismo, pp. 75-168.

${ }^{26}$ Biblioteca Nacional de Madrid (=BNM), ms. 1114, f. 62v.

${ }^{27}$ Michel RubELLIN, Au temps où Valdès n'etait pas hérétique: hypothèses sur le rôle de Valdès à Lyon (1170-1183) en Inventer l'hérésie? Discours polémiques et pouvoirs avant l'Inquisition,. (dir. Monique ZERNER), Collection du Centre d'Etudes Médievales de Nice, Volume 2, Nice, 1998, pp. 193-218.
} 
palabras que el Padre y el Hijo y el Espíritu Santo son tres personas, un solo Dios ${ }^{28}$.

Los artículos profesados son la unidad de la naturaleza y la divinidad de cada una de las tres personas de la Trinidad, que se equiparan a Dios. Este Dios, creador -creatorem et factorem- de todas las realidades visibles e invisibles, celestes y aéreas, acuáticas y terrenas es autor del Antiguo y del Nuevo Testamento así como de la ley de Moisés y de los profetas ${ }^{29}$.

En ambas y cada una de las naturalezas, es decir, Dios y Hombre, es una sola persona, un hijo, un Cristo, un solo Dios con el Padre y el Espíritu Santo, autor y gobernador de todas las cosas ${ }^{30}$.

La profesión de Pedro tiene en sus orígenes un claro objetivo; pretendía resumir el dogma católico en un momento en el que la Iglesia cátara estaba presente en Europa. La idea de la unicidad de Dios está en confrontación con el catarismo. Durand desarrolló la teología trinitaria en el prólogo del Antiheresis por ser el primero de los artículos de Valdés y porque fue el credo inicial de su teología, y de hecho, uno de los elementos fundamentales de la obra de Durand ${ }^{33}$. Por esta razón se comprende que incluya como prólogo en su tratado contra la herejía esta profesión de fe. A pesar de que el movimiento valdense fue catalogado como una herejía, en sus orígenes tuvo una voluntad ortodoxa y quería dejar clara la subordinación eclesiástica a Roma:

Creemos con el corazón y confesamos con la boca a una sola iglesia católica, santa, apostólica e inmaculada, fuera de la cual creemos que nadie se puede salvar ${ }^{32}$.

A continuación presenta el fundamento del grupo de Valdés: la pobreza absoluta:

Y porque, según el apóstol Santiago la fe «sin obras está muerta» renunciamos al siglo y a todo lo que poseíamos, y tal como ha sido aconsejado por

\footnotetext{
${ }^{28} \mathrm{BNM}$, ms. 1114, f. 1. "In nomine patris et filii et spiritus sancti atque beatissime semperque virginis marie. Pateat omnibus fidelibus, quod ego valdesius et omnes fratres mei, prepositis nobis sacrosanctis evangeliis, corde credimus, fide intelligimus, ore confitemur et simplicibus verbis affirmamus patrem et filium et spiritum sanctum tres personas esse".

${ }^{29} \mathrm{BNM}$, ms. 1114, f. 1. "Patrem quoque et filium et spiritum sanctum unum deum, de quo nobis sermo, esse creatorem, et factorem, et gubernatorem et, loco congruo et tempore, dispositorem omnium visibilium et invisibilium, celestium et aeriarum, aquaticarum et terrenarum, corde et ore credimus et confitemur. Novi et veteris testamenti, idest legis moisi et prophetarum et apostolorum, unum eundemque et deum auctorem credimus, qui in Trinitate, ut dictum est, permanens, omnia creavit"

${ }^{30} \mathrm{BNM}$, ms. 1114, f. 1. "Simul in eo utriusque nature, idest deus et homo, una persona, unus filius, unus christus, unus deus cum patre et spiritu sancto, omnium rector et autor"

${ }^{31} \mathrm{C}$. ThOuZELlier, La profession trinitaire du vaudois Durand de Huesca en Hérésie et hérétiques, Roma, Edizioni di Storia e Letteratura, 1969, pp. 53-79.

${ }^{32} \mathrm{BNM}$, ms. 1114, f. 2. "Unam ecclesiam chatholicam, sanctam, apostolicam, et immaculatam, extra quam neminem salvari credimus".
} 
el Señor, lo distribuimos a los pobres, y decidimos ser pobres, de modo que no nos preocupamos del mañana, ni de poseer oro ni plata, ni nada más fuera de la comida o del vestido cotidiano de quien quiera proporcionárnoslo. Nos proponemos observar como preceptos los consejos evangélicos ${ }^{33}$.

La pobreza evangélica fue la característica principal de la valdesía, y también el de las futuras comunidades apostólicas del siglo XIII, entre las que se encontraron los Pobres Católicos y los franciscanos. A continuación siguen otros artículos profesados que reafirman la ortodoxia religiosa y están en pleno debate con el catarismo: el bautismo a los niños, la salvación por el juicio final o la aprobación de los sacramentos religiosos.

En este prólogo podemos observar que los preceptos de Valdés son los preceptos que Durand utilizó como fundamento para su comunidad apostólica que presentará en su reconciliación con Roma después de Pamiers. Además, los puntos que recoge Durand en esta profesión serán desglosados a lo largo del Liber Antiheresis como defensa del cristianismo. A pesar que desde sus inicios, la valdesía tuvo un carácter anticátaro y ortodoxo, ambos movimientos fueron perseguidos por la Iglesia Católica, fueron confundidos durante muchos siglos y ambos fueron tachados como herejía.

El Liber Antiheresis se presenta como un tratado de polémica contra la herejía. Aunque Durand, como hemos comentado, no cite explícitamente al catarismo, el tratado está dirigido contra la herejía cátara del Languedoc que afirma la existencia de dos dioses. Con un gran conocimiento de las fuentes y con una gran cultura eclesiástica Durand reúne en esta obra numerosas citas de la Biblia, de los Santos Padres de la Iglesia como San Agustín, Pedro Lombardo, San Jerónimo, Boecio, e incluso San Isidoro. A esto se añade un gran conocimiento gramatical que utiliza constantemente para razonar el significado etimológico de las palabras.

Los cinco capítulos que componen la segunda parte del libro desarrollan plenamente el debate teológico contra el catarismo ${ }^{34}$. Durand ataca los puntos fundamentales de su doctrina: la existencia de un único Dios frente al dualismo cátaro; sobre la caída de los ángeles que se precipitaron desde el cielo; contra aquellos que repudian el Antiguo Testamento y para terminar, Durand desarrolla la teología de la resurrección futura en el día del juicio final hecho que le remite directamente al problema de la salvación. Éste es el debate. Todos estos argumentos sirven para atacar al catarismo, ya que todos ellos están directamente relacionados con la doctrina de este movimiento. En el Liber Antiheresis se integran también los argumentos cátaros. Durand nos advierte que

${ }^{33} \mathrm{BNM}$, ms. 1114, f. 2. "Et quia fides secundum iacobum apostolum «sine operibus mortua est», seculo abrenunciavimus et que abebamus, velut a domino consultum est, pauperibus erogavimus et pauperes esse decrevimus, ita ut de crastino solliciti esse non curamus, nec aurum nec argentum vel aliquid tale preter victum et vestitum cotidianum a quoquam accepturi sumus. Concilia quoque evangelica velut precepta servare proposuimus".

${ }^{34}$ C. THOUZELLIER, Controversies; ver apéndice donde se encuentra la transcripción de la esta segunda parte del manuscrito de Madrid Liber Antiheresis, p. 166 y ss. 
para decirlo con más claridad, aunque sea una abominación, sin embargo, para que con mayor facilidad sean evitados quienes afirman tales cosas y se cuide uno de ellos, voy a divulgar su doctrina ${ }^{35}$.

Gracias a su obra conocemos de forma precisa aspectos de la doctrina del catarismo. Según Durand, los cátaros:

Creen, según hemos oído, y dicen a algunos de sus seguidores que crean, en la existencia pareja de dos dioses sin principio, uno bueno y el otro malo, y tal como hay una trinidad buena, así dicen que hay una trinidad mala, a la que identifican sin dudar con el dios de este mundo y príncipe de las tinieblas. Y dicen que éste entró en la morada del Padre celestial para seducir a los ángeles y creen que corrompió a un cierto número. Y por este motivo dicen que el Padre se alzó contra él y lo arrojó de la patria celeste junto con los ángeles a quienes había seducido ${ }^{36}$.

La existencia de dos dioses que son irreconciliables entre sí es el fundamento del dualismo cátaro. De estos dos Dioses se distinguen dos creaciones diferentes, dos mundos, el mundo material y el mundo espiritual. Para los cátaros, que han sido trasladados del cielo a esta tierra, que llaman extranjera ${ }^{37}$, el origen del mundo de la materia tiene un origen distinto al del espíritu:

porque dicen que las almas pecaron al principio del mundo y se hicieron merecedoras de cuerpos desde el cielo a la tierra y diversas ataduras, declarando que por esta causa fue creado el mundo ${ }^{38}$.

Para Durand, como para los polemistas católicos:

esto es herejía, falsedad y mentira. Jamás ninguno de los santos espíritus que se hallan en la presencia de Dios creyó tales cosas, ni afirmó que debían creerse ${ }^{39}$.

Por lo que desarrolla entonces su teología partiendo de la unicidad de Dios y fundamentado en las Sagradas Escrituras:

\footnotetext{
${ }^{35} \mathrm{BNM}$, ms. 1114, f. 62r. "Et ut lucidius dicam, quamvis abhominatio sit, tamen ut facilius qui talia asserunt devitentur et ab eis caveatur, eorum intellectum divulgabo".

${ }^{36}$ Ibidem, f. $62 \mathrm{v}$. "Credunt enim, ut nostris auribus insonuit, et quibusdam credentibus suis dicunt ut credant similiter, duos esse deos sine inicio, unum bonum et alterum malum, et sicut est bona trinitas, ita dicunt esse malam trinitatem, quam deum huius mundi et principem tenebrarum affirmant. Et ipsum dicunt esse ingressum curiam Patris celestas, ad decipiendos angelos et quosdam fecisse fornicari credunt. Et ob hanc causam Patrem dicunt surrexisse contra eum, et eum de patria celesti depulisse et angelos quos seduxerant".

${ }^{37}$ Ibidem, f. 58 v. "heretici dicentes se ese de celo translatos in hanc terram quam dicunt alienam

${ }^{38}$ Ibidem, f. 50 r. "qui dicunt animas in mundi principio peccasse et de celis usque ad terras diversaque vincula corpora meruisse eaque causa factum ese mundum confitentes

${ }^{39}$ Ibidem, f. 62r "Set hoc est heresis falsitas mendacium. Nusquam enim aliquis sanctorum spirituum in conspectu Dei assistentium talia credidit, nec credenda esse asseruit"
} 
No es así, porque nada existe sin un principio, excepto el Padre, el Hijo y el Espíritu Santo. Todo espíritu, tanto los buenos como los malos, fueron creados y modelados por Dios ${ }^{40} \ldots$. Hay que mostrar de qué manera se precipitó y por qué causa los santos varones declaran que cayó. Cayó por propia culpa y fue condenado por la eternidad. Pues Dios, según algunos, tomó del cielo supremo la materia de los ángeles y los creó como espíritus buenos y preclaros; de los cuales uno, llamado Lucifer (portador de luz), viéndose más brillante y luminoso que los demás, se creció en arrogan$\operatorname{cia}^{41} \ldots$

Por esa soberbia cayó del cielo [él] y todos cuantos ángeles estuvieron de acuerdo con él. Y fueron convertidos en demonios. Antes no existía el diablo ni el espíritu maligno. Y puesto que pecaron por propia voluntad y no por persuasión de nadie, fueron condenados por la eternidad ${ }^{42}$.

El debate teológico se centra en el origen del mal. ¿Cómo podía el catarismo reconciliar los atributos de Dios, el Dios bueno con la realidad y la maldad de este mundo? No podían. De allí el doble principio creador para explicar la diferencia que existía en esencia entre el mundo material y el mundo espiritual. La negación del mundo material era un ataque directo contra toda la doctrina de la Iglesia Romana. Por esta razón Durand tiene la necesidad de refutar con conceptos como el "sempiterno" donde la influencia de autores como Isidoro de Sevilla está presente.

Si objetan que en Ezequiel se dice: "El cual se hizo sempiterno enemigo suyo" (cf. Ez. 35, 5) y por ello afirman que el diablo no tuvo principio, sepan qué significa el término 'sempiterno'. Pues 'sempiterno' no significa 'sin principio'. Hay una diferencia entre 'eterno', 'sempiterno' y 'perpetuo'. 'Eterno' es lo que carece de principio y fin, como Dios. 'Perpetuo' es lo que comienza con el tiempo y nunca se termina, como el mundo. 'Sempiterno' es lo que tiene un principio bajo el tiempo y no tendrá fin, como el alma; y así el diablo es un enemigo // sempiterno, que tiene principio pero no $\mathrm{fin}^{43}$.

${ }^{40}$ Ibidem, f. 62v "Non enim ita est, quia nullus sine inicio, nisi Pater et Filius et Spiritus sanctus. Omnis (sic) enim spiritus sive boni sive mali a Deo creati".

${ }^{41}$ Ibidem, f. $63 \mathrm{r}$ "Set ostendendum est qualiter corruit et ob quam causam sancti viri eum cecidisse testificati sunt. Propria enim culpa cecidit et in eternum dampnatus est. Nam Deus materiam abgelorum, iuxta quosdam, sumpsit e cello empire et eos spiritus bonos creavit atque preclaros; quorum unus, qui Lucifer, quasi ferens lucem, vocabatur, cum cognovisset se clariorem ac lucidiorem ceteris, in arrogantia elevates est".

${ }^{42}$ Ibidem, f. 64r "Et hob hanc superbiam cecidit de cello et omnes angeli quotquot consenserunt ei. Et demones facti sunt. Non enim antea diabolus erat, nec malignus spiritus. Et quia sponte et non aliquo suadente peccaverunt, in eternum dampnati sunt". En el prólogo de Valdés aparece esta misma idea: "Diabolum non per condicionem, set per arbitrium malum esse factum credimus".

${ }^{43}$ Ibidem, f. 53r. "Si obiciunt quod in Ezechiel dicitur: «Qui factus est ei inimicus sempiternus» (cf. Ez. 35, 5) et ideo dicant diabolum non habuisse inicium. Dișcant quo modo diffinitur hoc nomen 'sempiternus'. Nam 'sempiternus' non diffinitur sine inicio. Est autem differentia inter 'eternum' et 'sempiternum' et 'perpetuum'.'Eternum'est quod caret principio et fine, ut Deus. 'Perpetuum' est quod habet principium cum tempore et numquam finitur, ut mundus. 'Sempiternum' est quod habet inicium sub tempore nec habebit finem, ut anima; et ita diabolus est inimicus // sempiternus, habens inicium, set non finem". 
El método que utiliza Durand es, en definitiva, el método del gran polemista católico; primero reproduce los argumentos de los herejes para luego refutarlos a partir de las Autoridades:

Que impongan silencio, pues, a semejante charlatanería. Y pues creemos que bastan las precedentes autoridades para probar la citada doctrina ${ }^{44}$.

Todo esto convirtió a Durand en un terrible adversario. Sus controversias tuvieron una gran eficacia gracias al empleo de un modelo muy eficaz ${ }^{45}$. En primer lugar, el uso de las Sagradas Escrituras, la Biblia como principal arma de ataque. En segundo lugar, con un conocimiento profundo de gramática latina y griega, que le permitía discutir con un valor añadido, rebatir argumentos apelando al origen y significado de la palabra. Para Durand, el dogma cátaro no se fundamentaba en las Sagradas Escrituras, sino en una interpretación mutilada de las mismas. Hay un tercer elemento que determina esta eficacia, y es la vida predicadora que llevó a cabo Durand. Los Pobres Católicos fueron la comunidad con la que llevó a cabo su ideal apostólico, basado en la pobreza como había hecho años antes Pedro Valdés. Su actividad predicadora consiguió la conversión de multitud de valdenses al catolicismo.

Pero la actividad literaria de Durand no termina aquí. La influencia del Liber Antiheresis va mucho más allá de ser un tratado más de polémica de la época. El análisis crítico del Liber revela la gran importancia que este libro tuvo para otros tratados posteriores y nos muestra también, el primer estadio de la controversia que se desarrolló durante los años sucesivos contra la herejía. El Liber Antiheresis, decía Selge, fue un primer índice, un primer manual para la lucha contra la herejía cátara, y una defensa de las verdades católicas ${ }^{46}$ y sirvió como base para que otros autores escribieran sus obras. De Durand parece que es otro manuscrito que también se encuentra en Madrid, el Opusculum contra hereticos et eorum errores ${ }^{47}$, un breve opúsculo contra los errores de la herejía que conforma el capítulo III del manuscrito titulado Expositio super Cantica Canticorum. El documento fue escrito entre $1210 \mathrm{y}$ 1215 , y es una ampliación de algunos aspectos que Durand presenta en su Antiheresis, concretamente del libro II, en el que encontramos desarrollada la polémica contra el catarismo, pero esta vez divididos en 21 capítulos y en espacio más reducido ${ }^{48}$. La importancia de este breve manuscrito radica principalmente en ser la base para que otros polemistas elaboren sus obras.

\footnotetext{
${ }^{44}$ Ibidem, f. 66r. "Sileant ergo ab huiusmodi con // viciis. Et quia predictas auctoritates ad predictam rationem probandam sufficere credimus".

${ }^{45} \mathrm{M}-\mathrm{H}$. VIACAIRE, Les Vaudois et Pauvres Catholiques contre les Cathares (1190-1223), "Cahiers de Fanjeaux", 2 (1967), pp. 244-271.

${ }^{46} \mathrm{~K} .-\mathrm{V}$. Selge, L'apport du Liber Antiheresis de Durand, "Cahiers de Fanjeaux", 2 (1967), pp. 228-3i.

${ }^{47}$ BNM ms. 6911, ff. 62-128.

${ }^{48}$ A. Dondaine, Durand, pp. 256-259.
} 
Este es el caso de su compañero Ermengaud de Beziers ${ }^{49}$, que utilizó como base este opúsculo del oscense para escribir su Contra Hereticos, otro tratado dirigido contra los cátaros ${ }^{50}$. La influencia del Antiheresis, por lo tanto, está muy presente en esta obra de Ermengaud.

\section{LOS POBRES CATÓLICOS \\ Y LA ESCUELA DE LA CORONA DE ARAGÓN}

La reconciliación de Durand con Roma después de Pamiers y el proceso de constitución de los Pobres Católicos lo conocemos bien por la correspondencia de Inocencio III. En 1207, después de la experiencia de Pamiers, y una vez escrita su primera obra, Durand con algunos compañeros, viajaron a Roma para visitar a Inocencio III y presentar su reconciliación de fe con la Iglesia. El 18 de diciembre de 1208 Inocencio III escribía al arzobispo de Tarragona, Ramón Rocabertí, y a los obispos de sus diócesis sufragáneas - Tortosa, Urgell y Huesca-, para que reconocieran y se reconciliaran con la Iglesia de Durand de Huesca y sus compañeros ${ }^{51}$ que Inocencio III llamó a partir de 1208 Pauperes Catholici. En esta carta se hacía mención a la reconciliati ecclesiastice unitati, la reconciliación de Durand con la Iglesia y también incluye su prepositium conversationis, esto es, su profesión de fe. Es interesante comparar la profesión de Durand con la de Pedro Valdés que incluye en su Antiheresis, ya que ambas son muy parecidas. Básicamente sigue el mismo esquema; empieza con la misma concepción trinitaria de la Iglesia, un elemento muy importante para Durand, después sigue reproduciendo de forma idéntica los preceptos de Valdés, remarcando, eso sí, que creemos con el corazón y confesamos con la boca una Iglesia, no herética, Santa Romana Apostólica. Para Durand la predicación se convierte en una necesidad, así como la disputa para confundir al adversario de la Iglesia. Él y su grupo habían decidido consagrarse enteramente al estudio, a la lectura, a la predicación, a la enseñanza y a la discusión contra todos los errores de las sectas.

Sin embargo, no todos los miembros de esta naciente comunidad religiosa eran clérigos. La incorporación de laicos en comunidades religiosas fue una problemática que estuvo muy presente en la época; el caso de Valdés es significativo. Pero también, hubo teólogos como el parisino Alain de Lille que aceptaron la predicación por parte de laicos. Los Pobres Católicos no estuvieron exentos de esta polémica.

${ }^{49}$ Conocemos los nombres de los compañeros de Durand por la carta de Inocencio III con fecha 12 de mayo de 1210, entre los que se encontraba Ermengaudum, en D. MANSILLA, $o b$. cit., doc. 433 , p. 461 .

${ }^{50} \mathrm{C}$. THOUZELLIER, Le «Liber antiheresis» de Durand de Huesca et le «contra hereticos» d'Ermengard de Beziers, "Revue d'Histoire Ecclésiastique", LV/1 (Louvain, 1960), pp. 130-141.

${ }^{51} \mathrm{D}$. MANSILlA, La documentación, doc. 394, pp. 410-414; J. VENTURA, La valdesía, pp. 298-299. 
Esta disputa contra el adversario, continua Durand, tiene que ser realizada por los hermanos doctores instruidos. Pero además de la formación de clérigos dedicados a la predicación y a la polémica, los Pobres Católicos dedicaron su atención a los pobres y a las necesidades humanas, constituyendo casas, hospitales e iglesias. En la misma profesión también queda definido el hábito religiosum et modestum que caracterizará a la comunidad. Castidad, ayunos, oraciones que siguen los preceptos evangélicos o los ropajes viejos como los que utilizaban los Pobres de Lyon, son los elementos más significativos. Los hermanos que quieran unirse al grupo estaban en la obligación religiosa et ordinate vivendo permaneat, de vivir en sus casas de forma religiosa, así como misericordia dispensando, manibus laborando. Esto es característico de esta comunidad, en la que se impone la obligación de mostrarse bondadoso y compasivo al tiempo que se realizan las tareas religiosas. Durand impone esta regla a aquellos que querían unirse a su comunidad pero esta práctica era poco característica de las órdenes religiosas del momento, en cambio lo fue para las órdenes posteriores. ¿Conocía esta práctica del catarismo y la adaptó a su comunidad? Es muy probable que sí, pues la combinación entre el trabajo en el hogar y la devoción religiosa era algo típicamente cátaro. En la carta también se menciona la obligación de pagar a la Iglesia sus diezmos, primicias y ofrendas que le pertenezcan, para no romper la vinculación con Roma. Con esta comunidad, el oscense quería formar un grupo de clérigos con una preparación teológica necesaria para hacer frente a la herejía. Estos clérigos eran los destinados a realizar la predicación y la disputatio.

En las cartas de Inocencio III aparece el término de socius para referirse a los compañeros de Durand, siguiendo el mismo modelo que utilizaban los cátaros. El socius era el joven que acompañaba al anciano cátaro. De esta comunidad dice Jordi Ventura que:

el grupo de valdenses convertido junto con Durán de Huesca iban a poner en práctica una de las ideas favoritas de Inocencio III: la formación de una comunidad católica que imitase la organización y los principios morales de los heterodoxos. Comunidad que se halla en los orígenes de las primeras órdenes mendicantes y, sobre todo, de sus órdenes terciarias ${ }^{52}$.

Y de hecho, en la carta de diciembre de 1208, este modelo queda bien patente.

Los Pobres Católicos salieron de Roma con la aprobación papal a principios de 1209. Pasaron por distintas ciudades de la Lombardía en las que Durand empezó a convertir al catolicismo a más de un centenar de valdenses. En ese mismo año de 1209, llegaron a Occitania, y se instalaron en el Aude no sin resistencia por parte del arzobispo de Narbona que se quejaría al papa de la actitud de Durand. Estas quejas motivaron la carta del 5 de julio de 1209 dirigida al arzobispo de Tarragona y sus sufragáneos en la que insistía que

${ }^{52}$ J. VentURA, La valdesía, p. 297. 
procedieran con la máxima cautela en la reconciliación de Durand y sus compañeros $^{53}$. El arzobispo de Narbona, así como los de Beziers, Usés, Nimes y Carcasona habían mandado a dos monjes cistercienses a quejarse al papa de que la comunidad de Durand eludía las disciplinas canónicas, que se habían corrompido ya que se inclinaban hacia los valdenses, y que protegían a los monjes que habían huido de sus monasterios. Éstas eran las quejas que se citaban. Otra carta con la misma fecha, esta vez dirigida a Durand y sus compañeros y enviada también al arzobispo de Tarragona, ordenaba que el grupo evitara todo trato con los herejes albigenses ${ }^{54}$, justo cuando empezaba en verano de 1209 la cruzada contra los cátaros en Occitania.

A lo largo de 1210 las quejas se hicieron más frecuentes. En esta situación, Durand realizó su segundo viaje a Roma para encontrarse nuevamente con Inocencio y buscar su respaldo. El 12 de mayo de 1210, el papa mandaba al arzobispo de Tarragona y sus sufragáneos, que Durand y su comunidad fueran considerados como católicos ${ }^{55}$. Los Pobres Católicos quedaban integrados en la Iglesia de Roma. Del mismo día hay una segunda carta que sirve para asegurarse que Durand de Huesca y su compañero, Guillermo de San Antonio, quienes habían abjuraron de sus errores, no fueran molestados en su trabajo. ${ }^{56}$ A partir de 1210, los Pobres Católicos se organizaron en Cataluña y Aragón, en Narbona y también en Lombardía para empezar su actividad misionera.

En 1212 Durand realizó su tercer viaje a Roma. En mayo de ese mismo año, salieron de la corte pontificia un mínimo de seis cartas relacionadas con él. En 25 de mayo Inocencio escribió una carta al obispo de Elna, en el condado del Rosellón, para que concediera el permiso a Durand y su grupo para que pudieran instalarse en esta ciudad y emprender su vida religiosa, aunque advirtiéndole que procedieran con las debidas cautelas ${ }^{57}$. En 1212 empezaba la actividad más fructífera de los Pobres católicos en el norte de Cataluña, cuyo centro fue Elna. Inocencio escribía el 30 de mayo al rey Pedro, illustri regi Aragonensi, para que no permitiera que Durand fuera molestado en su nuevo proyecto ${ }^{58}$. Al mismo tiempo mandaba a Durand denunciar los excesos de algunos reconciliados que formaban parte de su comunidad al obispo rosellonés para que fueran corregidos por él. ${ }^{59} \mathrm{El}$ problema con los reconciliados fue uno de los más comunes que los Pobres Católicos tuvieron que enfrentarse; en 1209 dos monjes cistercienses ya se habían quejado al papa. La incorporación de valdenses convertidos sin estar debidamente reconciliados con la Iglesia católica fue un problema constante.

\footnotetext{
${ }^{53}$ D. MANSILlA, La documentación, doc. 404, p. 420-1.

${ }^{54}$ Ibidem, doc. 405, pp. 421-5.

${ }^{55}$ Ibidem, doc. 433, pp. 460-2.

${ }^{56}$ Ibidem, doc. 434, pp. 462-3.

${ }^{57}$ Ibidem, doc. 474, pp. 504-6.

${ }^{58}$ Ibidem, doc. 476, pp. 506-7.

${ }^{59}$ Ibidem, doc. 477, pp. 507.
} 
Con estas cartas, Inocencio mostraba su voluntad de remediar contra las quejas que recibía de esta comunidad. Otra de las cartas de 1212 se dirige al arzobispo de Narbona para que Durand sea tratado benignamente ${ }^{60}$ para que su comunidad pudiera trabajar en esta región. El mismo año, Inocencio tomaba bajo protección de la Santa Sede la persona y bienes de Durand y sus compañeros $^{61}$, y mandaba a los obispos de Barcelona y Huesca que admitieran a este grupo en el seno de la Iglesia. ${ }^{62}$ Es muy probable que con el paso del tiempo el grupo de Huesca acabara uniéndose al complejo asistencial de San Miguel $^{63}$, ya que ambos movimientos tuvieron mucho en común. Por otro lado, tan solo en esta carta, mandada al obispo Berengario del 30 de mayo, se recalca que Durand es un reconciliado de la secta Waldensium, la única mención tan explícita que Inocencio hace en sus cartas del pasado valdense de Durand. A mediados de 1212, los Pobres Católicos tenían el territorio preparado para instalarse y actuar.

La cruzada que durante esos años se desarrolló en Occitania contra el catarismo influyó en la actuación de los Pobres Católicos. Durand y su grupo nunca aprobaron la crueldad de la cruzada; su lucha para la conversión fue verbal y escrita. La exención militar que recibieron en 1208 les despojó de toda obligación de luchar en las guerras religiosas y políticas del Midi francés ${ }^{64}$. Los Pobres Católicos se dedicaron exclusivamente a los más necesitados, construyendo casas, hospitales para pobres, enfermos y niños abandonados, siempre con una iglesia. Constituyeron escuelas de estudio y gozaron de mucha simpatía popular. Nunca ejercieron la violencia. A pesar que el grupo padeció muchas dificultades y constantes enemigos, la intervención de Inocencio III y varios obispos en Roma protectores de su comunidad, facilitó su actividad.

Después de 1212, Durand desaparece de la correspondencia pontificia. Tampoco es mencionado en otras fuentes después de esta fecha. La muerte de Inocencio III en 1216, su principal protector, relegó la comunidad de Durand a un segundo plano. Siguió con protectores en la Curia Romana, pero ya no del pontífice. El siguiente papa, Honorio III ya no les menciona en sus cartas, aunque es muy probable que Durand hubiera realizado otro viaje a Roma durante la década de 1220, para que el cardenal Leo Brancaleone corrigiera el Liber Contra Manicheos. Finalmente Durand terminó por dedicarle esta última obra.

En uno de los primeros viajes que realizó a Roma, muy probablemente entre diciembre de 1208 y julio de 1209, Durand conoció, a través del mismo Leo Brancaleone, a Pedro de Capua, quien poco después llegaría a ser cardenal. Durand realizó una revisión de la obra de Pedro titulada Alphabetum

\footnotetext{
${ }^{60}$ Ibidem, doc. 478 , pp. 507-8.

${ }^{61}$ Ibidem, doc. 479, pp. 508.

${ }^{62}$ Ibidem, doc. 480 , pp. 508-9.

${ }^{63}$ E. SARASA, art. cit., p. 234.

${ }^{64}$ D. MANSILlA, La documentación, doc. 396, p. 415
} 
in artem sermocinandi. Su trabajo consiste en una revisión del Alphabetum y contiene una colección de Distinctiones bíblicas, en un manuscrito descubierto no hace mucho en la Universidad de Yale, con nombre Marston 266. Durand añadió un prólogo y dedicó la obra a Bernardo de Pavía, un importante canónigo y profesor de la universidad de Bolonia. Tan solo con este manuscrito, podemos comprobar los contactos que el oscense realizó durante sus viajes a Roma. Las Distinctiones eran significados figurativos de las palabras de las sagradas escrituras que se utilizaban con ejemplos durante las clases, y que Durand utilizará también en su última obra. Entre 1208 y 1213 debió realizar la revisión del trabajo de Pedro. Este tratado es atípico en la obra de Durand, pero nos muestra de forma excepcional su capacidad en introducirse en un ámbito que hasta hace muy poco nos era desconocido. A. y M. Rouse han mostrado en uno de sus trabajos cómo: muchos de los elementos del escrito y la decoración del Marston 266 sugieren que el manuscrito fue copiado en España ${ }^{65}$. ¿Es posible que fuera Elna este lugar?

La tercera gran obra de polémica que Durand escribió contra los cátaros fue el Liber contra Manicheos ${ }^{66}$. Escrita en torno a 1220 y 1224, los paralelismos con su primera obra escrita veinte años antes son muy patentes. Con un índice muy parecido, el libro incluye fragmentos de su primera obra, pero con algunas modificaciones ${ }^{67}$. Su estancia en Roma debió darle a conocer numerosas obras que terminarán por perfeccionar su conocimiento. Uno de los aspectos más destacables es que incluye un tratado cátaro anónimo ${ }^{68}$ que copió íntegro para refutarlo y que se ha conservado gracias a ello. Es un tratado en latín que debió hacerse con él hacia 1220 y 1222 y que circulaba durante esos años por la zona más meridional de Francia, concretamente en Narbona y fue escrito según Durand por un doctor manicheo. El polemista responde a la apología cátara siguiendo el mismo método que ya había empleado en el Antiheresis. En esta ocasión no incluye el prólogo de Valdés pero, a pesar de ello, nunca se olvidó de sus antiguos compañeros. Nunca los citará como herejes y su relación con ellos siempre estuvo presente.

\section{INFLUENCIA DE LA OBRA DE DURAND}

La estructura del Liber contra Manicheos difiere del Antiheresis. Habían pasado más de de veinte años desde que Durand escribió su primera

\footnotetext{
${ }^{65}$ M. A. RouSe, R. H. RouSE, The Schools, p. 104.

${ }^{66}$ De este manuscrito existen dos versiones, una en Paris (BN, 689) y otra en Praga (CXCV). La edición crítica a cargo de C. THOUZELLIER, Une Somme anti-cathare: Le livre contra manicheos de Durand de Huesca, Université catholique de Lovaina, 1964. El edición incluye el tratado anónimo cátaro y el tratado de refutación de Durand.

${ }^{67}$ A. Dondaine, Durand de Huesca, pp. 229 y sig.

${ }^{68} \mathrm{La}$ edición crítica del manuscrito anónimo cátaro copiado por Durand, antes de publicarse conjuntamente con la obra de Durand, en C. THOOUZELLIER, Un traité cathare inédit du début du XIII siècle, d'après le "Liber contra manicheos", de Durand de Huesca, Lovaina, Publications Universitaires de Louvain, 1961.
} 
obra. Los viajes a Roma, el estudio, el descubrimiento de bibliotecas y nuevos libros, son elementos añadidos a esta última obra. Es en esta obra donde Durand enumera los protectores de su comunidad que tuvo en la curia romana. Lo que nos interesa destacar del Liber contra Manicheos es que el tratado cátaro anónimo que contiene nos introduce en otros ámbitos que muestran la influencia que el catarismo pudo tener con otros movimientos, como por ejemplo los beguinos. El Alia Informatio Beguinorum es un tratado que Arnau de Vilanova compone en 1312 para la defensa de la comunidad y del modo de vivir beguino para hacer frente a los continuos ataques que los dominicos realizaban contra ellos. En este tratado, como ha mostrado Josep Perarnau, Arnau de Vilanova utiliza parte de un fragmento del texto cátaro anónimo que escribió Durand para refutar años antes. ${ }^{69}$ ¿Cuándo y cómo conoció Arnau de Vilanova la obra de Durand? El hecho que Arnau utilizara para la defensa del modo de vida beguino parte, por breve que sea, de un texto cátaro, plantea la posible relación que pueda existir entre el catarismo y el beguinismo. Es factible que Arnau conociera el texto cátaro a través de la lectura del Contra Manicheos. Pero también es cierto que existe una influencia constatada en las obras de Arnau de Vilanova con los grupos de franciscanos espirituales e iluminados de los reinos de la península, pero de forma más concreta con los beguinos, la orden terciaria de los franciscanos, con los que Arnau mantenía continuos contactos. Beguinos y cátaros tuvieron varios elementos en común; la dieta cartujana, la pobreza evangélica o la pertenencia de muchos de sus miembros a los paraires es bastante significativo. Es muy probable que muchos de los cátaros perseguidos, cuando la Iglesia cátara estaba ya completamente desarticulada a principios del siglo XIV, pudieran encontrar en el movimiento beguino una comunidad muy afín al modo de vivir del catarismo en diversas zonas de la Península Ibérica.

Uno de los casos más claros lo encontramos en Mallorca. Sabemos que Mallorca fue un lugar donde el movimiento beguino tuvo mucha presencia igual que el catarismo. El registro de la Inquisición de Pierre Cellan (1241-42) nos muestra dos datos sorprendentes al respecto. Raimonda, mujer de Boussoulens dice que mantuvo la fe de los perfectos en la casa de su marido en Mallorca, los adoró y comió con ellos ${ }^{70}$, igual como también hizo Durand de Broille ${ }^{71}$.

Pero esta relación no sólo la encontramos en Mallorca. Otro de los lugares fue Sicilia donde el beguinismo también tuvo una fuerte implantación, y donde Arnau de Vilanova, estuvo muy vinculado durante su última etapa ${ }^{72}$.

\footnotetext{
${ }^{69}$ Josep PERARNAU, L' «Alia informatio beguinorum» d'Arnau de Vilanova, Facultat de Teologia de Barcelona, Studia, Textus, Subsidia - II, Barcelona, 1978, pp.169-172.

${ }^{70}$ Jean DuVERNOY, L'Inquisition en Quercy, Hydre, 2001, p. 181. Sobre el catarismo en Mallorca ver el trabajo de Gabriel ALOMAR, Câtaros y occitanos en el reino de Mallorca, Ripoll Lluis Editor, Palma de Mallorca, 1978.

${ }^{71}$ J. DUVERNOY, Ibidem, pág. 207

${ }^{72}$ Arnau de Vilanova dedicó al monarca de Sicilia el tratado Informació Espiritual al rey Frederic de Sicilia, en Arnau de VILANOVA, Obres catalanes, vol I: Escrits religiosos, Barcelona, 1947, p.220-243
} 
Muchos beguinos, cuando fueron perseguidos por la Inquisición emigraron hacia Sicilia, igual como también hicieron muchos cátaros. El creyente cátaro Jean Mauri recordaba delante la Inquisición de Pamiers, como el cátaro que vivía en territorio catalán Raimond de Granadella le había comentado en alguna ocasión que "había muchos como él en Sicilia"73. Durante el reinado de Federico III, Sicilia se convirtió en un auténtico refugio para muchos de los perseguidos por la Inquisición, entre los que se encontraban un gran número de beguinos.

Otro aspecto a destacar es la utilización de la Biblia por Durand. Sus libros se fundamentan en las Sagradas Escrituras, y parece que para ello utilizó distintas versiones, de las que se puede destacar una Biblia de procedencia hispánica. La influencia del catarismo y de la valdesía en las primeras traducciones bíblicas es un hecho constatado ${ }^{74}$; ambos movimientos realizaron las primeras traducciones de los textos sagrados, los cátaros del Nuevo Testamento y otros textos apócrifos - excepto en el Liber de duobus principiis en el que el autor utiliza de forma excepcional el Antiguo y el Nuevo Testamento ${ }^{75}$ - y los valdenses la traducción de toda la Biblia así como otros textos de la patrística. En la Corona de Aragón, el 7 de febrero de 1234 apareció durante el reinado de Jaime I un decreto en el que se prohíbe la posesión del Viejo y el Nuevo Testamento en lengua vulgar ${ }^{76}$.

La realidad de hoy día es que no han sobrevivido biblias valdenses en catalán de esta época, y menos aún cátaras, pero no por ello no existieron. Lo que sí han perdurado son fragmentos en catalán como el Nuevo Testamento conservado en la Biblioteca de Cataluña, de origen beguino pero de época posterior a la que tratamos ${ }^{77}$. Por otro lado, los estudios que inició Samuel Berger hace más de cien años sobre las biblias catalanas y occitanas, mostraba la importancia de las versiones de la península en estas traducciones ${ }^{78}$. El padre Dondaine, a raíz de sus estudios ya sugirió el origen hispánico de la biblia occitana de Lyon, que podría ser parecida a las primeras biblias

${ }^{73}$ J. DUVERNOY, Le registre de L'Inquisition de Jaques Fournier, T. III., p. 874.

${ }^{74}$ Armand PUIG I TÀrRECH, La Bíblia a Catalunya, València I les Illes fins al segle XV. Lliçó inaugural, Curs 1997/98, Tarragona, Institut Superior de Ciències Religioses Sant Fructuós, Arquebisbat de Tarragona, 1997, pp. 89-104.

${ }^{75}$ Ver prólogo de Antoine DondaInE en A. DondaINE, Un traité Néo-Manichéen du XIIIe siècle le Liber de Duobus Principiis, Roma. Instituto Storico Domenicano, 1939, pp. 7-33. Espeçial mención tiene la influencia de unos de los textos apócrifos bogomilos y que utilizaron los cátaros en la región de la Corona de Aragón en Mathias DELCOR, L" "Ascension d'Isaïe» $\grave{a}$ travers la predication d'un évêque cathare en Catalogne au quatorzième siècle, "Revue de l'Histoire des Religions, CLXXXV-2/486 (1974), pp.157-178.

${ }^{76} \mathrm{C}_{\text {. BARAUT }}$, Els inicis, doc. 4. pp. 423-425: "ne aliquis libros veteris et novi testamenti in romancio habeat".

${ }^{77}$ Los fragmentos del NT en catalán se conservan en la BNC, ms. 740, en Josep PERARNAU EsPELT, Aportació al tema de les traduccions bibliques catalanes medievals, "Revista Catalana de Teologia" ( = RCat), Barcelona, Facultat de Teologia de Catalunya, 1978, pp. 17-98. Aunque el NT sea de origen beguino, las obras catalanas de Arnau de Vilanova, incluyendo la defensa de los beguinos (AIB), no se basaron en esta traducción beguina, ver Jaume MENSA VALLS, Les citacions bíbliques en català en les obres d'Arnau de Vilanova, "RCat" XIV (1989), pp. 517-526.

${ }^{78}$ Samuel BERGER, Les bibles provençals et vadois , "Romania”, 18 (1889), pp.353-422. 
hispánicas, entre las que se encontraría la de Huesca ${ }^{79}$. ¿Podría ser, cómo proponía Jordi Ventura, que Durand hubiera sido uno de los traductores de la biblia al catalán y hubiera facilitado las versiones hispánicas a sus compañeros del Languedoc en lengua vulgar? Instalado en Cataluña, Durand utilizó diferentes versiones bíblicas; el análisis de distintas partes del texto del Liber Antiheresis determina su origen hispánico, concretamente una versión católica ortodoxa que proviene de las primeras biblias visigóticas y que está en relación con los primeros códices hispánicos ${ }^{80}$. Los estudios de Christine Thouzellier sobre las Biblias que utilizó Durand para sus obras posteriores, el Contra Manicheos, nos muestra esta influencia hispánica, pero desmembrada en distintas versiones ${ }^{81}$. A falta de un estudio pormenorizado sobre la influencia de estas biblias, este aspecto aún está por resolver.

Las obras que Durand y su comunidad dejaron escritas sirvieron a Roma como un arma de ataque muy efectiva contra la herejía. Durand era un predicador, un polemista católico muy versado. Convencido de su fe estableció el carácter que para él tenía que definir a la Iglesia: la lucha contra la herejía, un ideal que mantendrá durante toda su vida, unido a la predicación. Pero sus prácticas canónicas, alejadas de la ortodoxia católica, así como sus vinculaciones con la valdesía, representaron un problema constante para Roma. De sus últimos años poco se sabe; Durand murió después de 1224, una vez finalizado su Contra Manicheos. El 26 de junio de 1237 Gregorio IX mandaba realizar un comisionado al prior provincial de los dominicos de la Tarraconense para que visite, corrija y reforme en esta circunscripción la orden de los Pobres Católicos, sospechosa de herejía pauperes de Lugduno paterna benignitate y para que les imponga una regla ${ }^{82}$. A pesar de ello, Inocencio IV emitió el 7 de mayo de 1247 una carta desde Lyon en la que confirma los privilegios y las propiedades de los hermanos católicos pobres de España, lo que nos indica que, a mediados del siglo XIII, aún tenían presencia en algunas regiones de España, si bien no especificaba en cuáles ${ }^{83}$. Pero en la provincia de Narbona parece que las cosas fueron distintas. Por una breve carta del 5 de junio de 1247, Inocencio IV, respondiendo a las quejas del arzobispo de Narbona y del obispo de Elna, mandaba prohibir su predicación. Los Pobres Católicos terminaron fusionándose con otras comunidades, como los agustinos y finalmente desaparecieron, según parece,

\footnotetext{
${ }^{79}$ A. Dondaine, Durand de Huesca, pp. 247 y sig.

${ }^{80} \mathrm{C}$. THOUZELLIER, Catharisme, pp. 447-451.

${ }^{81} \mathrm{C}$. THOUZELLIER, Les versions bibliques utilisées par Durand de Huesca au début du XIIIe siècle, en "Mélanges Eugène Tisserant", I (Studi e Testi 231), Città del Vaticano, 1964, pp.419435 .

${ }^{82}$ Santiago Domínguez SÁNCHEZ, Documentos de Gregorio IX (1227-1241) referentes a España, Universidad de León, 2004, doc. 675, pp. 538-539.

${ }^{83}$ Augusto QuINTANA PRIETO, La documentación pontificia de Inocencio IV (1243-1254), en "Monumenta Hispania Vaticana", Roma, 1987, vol. VII, doc. 397, pp. 396-397.
} 
sin ser considerados como una herejía ${ }^{84}$. Es significativo que el antiguo cátaro y Inquisidor Raynier Sacconi no incluya a los Pobres Católicos en su Summa de catharis $^{85}$, a pesar que cite a los valdenses y a los Pobres de Lombardía, una comunidad fundada por Bernard Prim que estuvo muy cerca de los Pobres Católicos y con un modelo muy parecido al de Durand ${ }^{86}$.

\section{CONCLUSIONES}

Después de la experiencia de Roma con Durand, las nuevas órdenes mendicantes serán el arma de ataque más efectiva de la Iglesia contra la herejía; en 1210 llegaba Francisco de Asís y en 1215 Domingo de Guzmán, pero esta vez ambos aceptados plenamente en la ortodoxia religiosa. Sin duda, la experiencia de Durand sirvió para ello.

¿Qué sabemos de esta comunidad que tenía una verdadera schola de textos en la Corona de Aragón? Lo cierto es que menos de lo que realmente fue. La figura de Durand y sus obras tienen un gran interés cultural para la Corona de Aragón y son de una gran importancia para el estudio del catarismo. El Liber Antiheresis fue un manual contra la herejía, un manual que como afirmaba Vicaire podía haber servido para instruir a los valdenses más incultos. ¿Cómo no pensar en su influencia en tierras de la Corona de Aragón? La actividad de Durand en la Corona de Aragón aún no ha sido valorada en su totalidad. Su obra, dice Christine Thouzellier, muestra la presencia de una verdadera oficina de textos y libros, todas las piezas creadas en Cataluña, por Durand y sus discípulos ${ }^{87}$.

A pesar de que se ha cuestionado sin mucho éxito el origen oscense de Durand ${ }^{88}$, la existencia de dos manuscritos suyos en Madrid, uno de ellos la primera versión y la base de una importante polémica que se desarrollará durante el siglo XIII contra el catarismo, así como las continuas cartas de Inocencio III a los obispos de la Corona de Aragón, revelan una vinculación de Durand con este territorio. Además, no hay que olvidar que el Liber Antiheresis, tiene una fuerte impronta gramatical catalana, así como sus sucesivas obras. En este artículo hemos pretendido aportar todos aquellos

${ }^{84}$ Elie BERGER, Les registres d'Innocent IV en Bibliothèque de l'École française d'Athènes et de Rome, vol. I, 1884, doc. 2.752, p. 410.

${ }^{85}$ Summa fratris Raynerii de ordine fratrum praedicatorum, De Catharis et Pauperibus de Lugduno en A. DONDÁINE, Un traité néo. manichéen, pp. 65-78. En este tratado sobre las herejías en Italia, Raynier vincula a los Pobres Lombardo s con los valdenses, en cambio no hace mención de los Pobres Católicos.

${ }^{86} \mathrm{Cap}$. XII- 1208-1210 profession de foi de Durand d'Huesca et de Bernard Prim en Giovanni GONNET, Enchiridion Fontium Valdensium, recueil critique des sources concernant les Vaudois au Moyen Age). Du IIIe Concile de Letran au Synode de Chanforan (1179-1532), Collana della Facoltâ Veldese di Teologia, I, Roma, 1958, pp. 130-140.

${ }^{87} \mathrm{C}$. THOUZELLIER, Le liber antiheresis pág.139

${ }^{88}$ Yves Dossat, A propos du prieur des Pauvres catholiques: Durand de Huesca ou de Losque en Rouerge?, "Bulletin Philologique et Historique (jusq'à 1610)", 1967, París, 1969. También publicado en Yves DosSAT, Eglise et hérésie en France au XIIIle siécle, Variorum Reprints Publication , 1982 
elementos que hasta el momento así lo muestran. Del Liber Antiheresis en su versión madrileña, aun no existe una edición crítica completa, a pesar de la riqueza de su información y de ser una fuente de primera mano en España para comprender la doctrina del catarismo y los inicios de la valdesía. Tampoco existe del Opusculum contra hereticos. Antonie Dondaine juntamente con Christine Thouzellier habían trabajado sobre los manuscritos pero las circunstancias de su fallecimiento no permitió finalizar con todo el trabajo que ambos historiadores habían empezado. Queda todavía mucho por hacer.

Fecha de recepción del artículo: mayo 2008.

Fecha de aceptación y versión final: febrero 2009. 